\title{
Non-Photochemical Laser-Induced Nucleation of sulfathiazole in water/ethanol mixture
}

Li Wenjing ${ }^{1,2}$, Aziza Ikni ${ }^{1,2 \#}$, Philippe Scouflaire ${ }^{1,3}$, Shi Xiaoxuan ${ }^{1,2}$, Nouha El Hassan ${ }^{1,2}$, Pascale Gemeiner ${ }^{1,2}$, Jean-Michel Gillet ${ }^{1,2}$, Anne Spasojević-de Biré $e^{1,2 *}$

${ }^{1}$ Université Paris-Saclay, CentraleSupélec, Campus de Châtenay, Grande Voie des Vignes, 92295 Châtenay-Malabry, France

${ }^{2}$ CNRS, UMR 8580, Laboratory “Structures Propriétés et Modélisation des Solides” (SPMS), Grande Voie des Vignes, 92295 Châtenay-Malabry, France

${ }^{3}$ CNRS, UPR 288, Laboratory “Energétique Moléculaire et Macroscopique, Combustion” (EM2C), Grande Voie des Vignes, 92295 Châtenay-Malabry, France

* Corresponding author \# actual address: CINaM-CNRS, UMR 7325, Aix-Marseille Université, Campus de Luminy, F-13288 Marseille, France.

\section{Supplementary material}




\section{Table S1}

Equations and R-factors of the linear regression of the $\operatorname{Ind}_{50}$ of Figure $7 \mathrm{a}$.

\section{Table S2}

Theoretical interaction energy $\left(\mathrm{kJ} \cdot \mathrm{mol}^{-1}\right)$ for STZ polymorphs II, III and IV.

\section{Figure S1}

NPLIN publications ${ }^{3-54}$ growth (1996-2015) according to definition in Scheme 1.

\section{Figure S2}

Absorption spectrum of a STZ dissolved in water/ethanol $(\mathrm{v} / \mathrm{v} 1: 1)$ realized with a Jasco spectrophotometer V630 bio.

\section{Figure S3}

Experimental set-up, details. (4) mirror, (6) inverted microscope

\section{Figure S4}

Raman spectra of the STZ different polymorphs.

\section{Figure S5}

Van't Hoff equation solubility fit ( $\left.\mathrm{y}=-5.88 \mathrm{x}+22.01, \mathrm{R}^{2}=0.988\right)$.

\section{Figure S6}

Schematic representation of the nucleation site. Step 1. The STZ molecules agglomerate in a cluster just after the irradiation. Step 2. The STZ nucleates and crystals grow. Step 3. The STZ crystal becomes bigger and falls to the bottom of the tube. Step 4. The STZ crystal is on the bottom of the tube where the camera is focalized. The crystal then continues to grow. The scheme is not at the scale.

\section{Figure S7}

Representation of the coefficient of the linear fit of Figure 7. A vertical line indicates that the fit lines are parallel.

\section{Video S1}

Experimental demonstration of a NPLIN nucleation of STZ in water/ethanol. $\mathrm{T}=25^{\circ} \mathrm{C}, \mathrm{SS}=$ $170 \%, \mathrm{t}_{\text {irr }}=5 \mathrm{~s}$, Energy density $=0.23 \mathrm{GW} \cdot \mathrm{cm}^{-2}$, sample volume $=1 \mathrm{ml}$. 
Table S1

Molecule

STZ w/e

CBZ me

CBZ ac

CBZ me

CBZ ac

STZ w/e polarization

CP

LP

LP

CP

CP

LP
Fit equation

$\mathrm{y}=-0.0115 \mathrm{x}+1.710$

$y=-0.0105 x+1.543$

$y=-0.0100 x+1.500$

$y=-0.0077 x+1.125$

$y=-0.0075 x+1.125$

$y=-0.0050 x+0.770$
Agreement factor

$\mathrm{R}^{2}=0.99436$

$\mathrm{R}^{2}=0.98145$

$\mathrm{R}^{2}=1.00000$

$\mathrm{R}^{2}=0.99689$

$\mathrm{R}^{2}=1.00000$

$\mathrm{R}^{2}=1.00000$ 


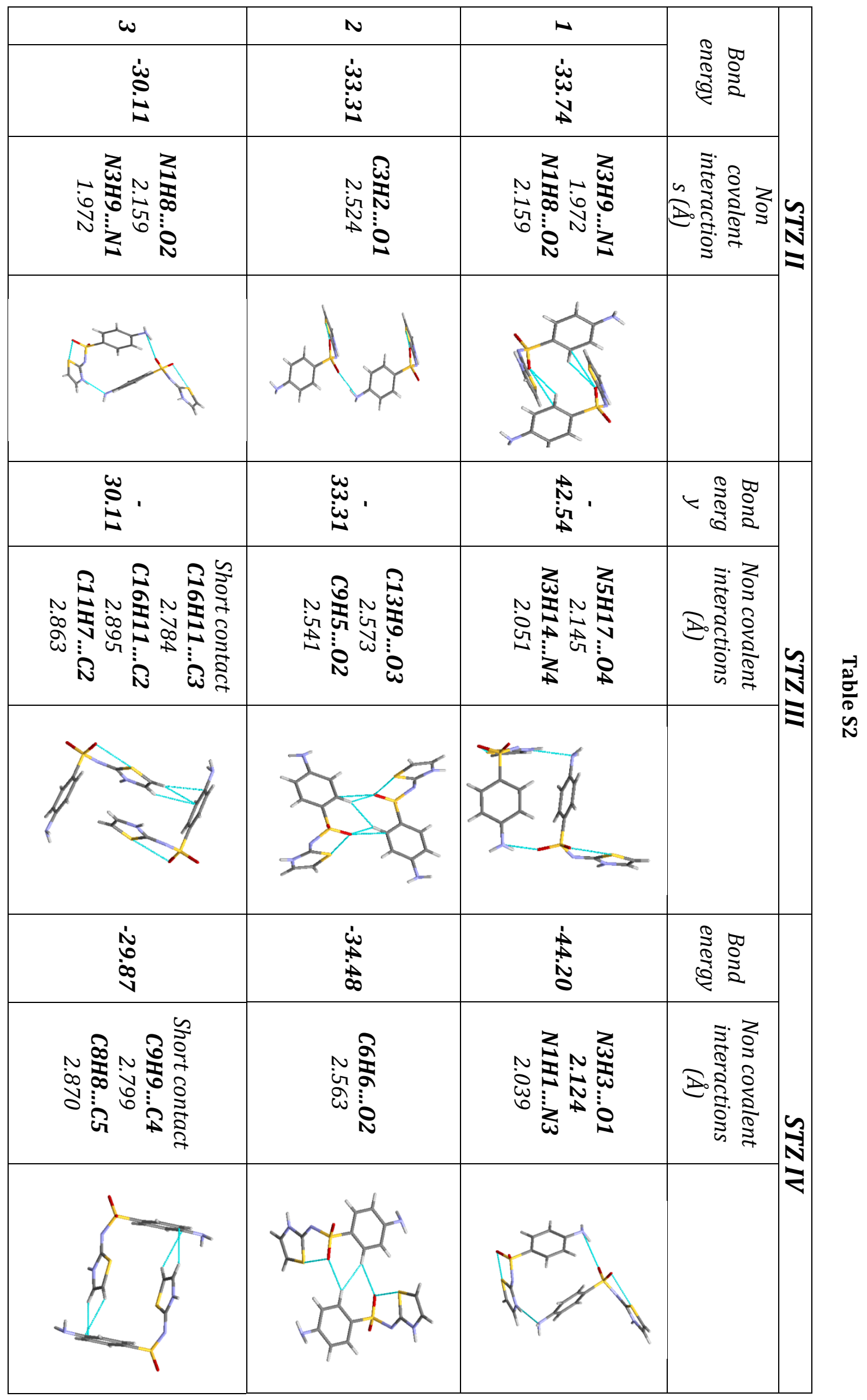




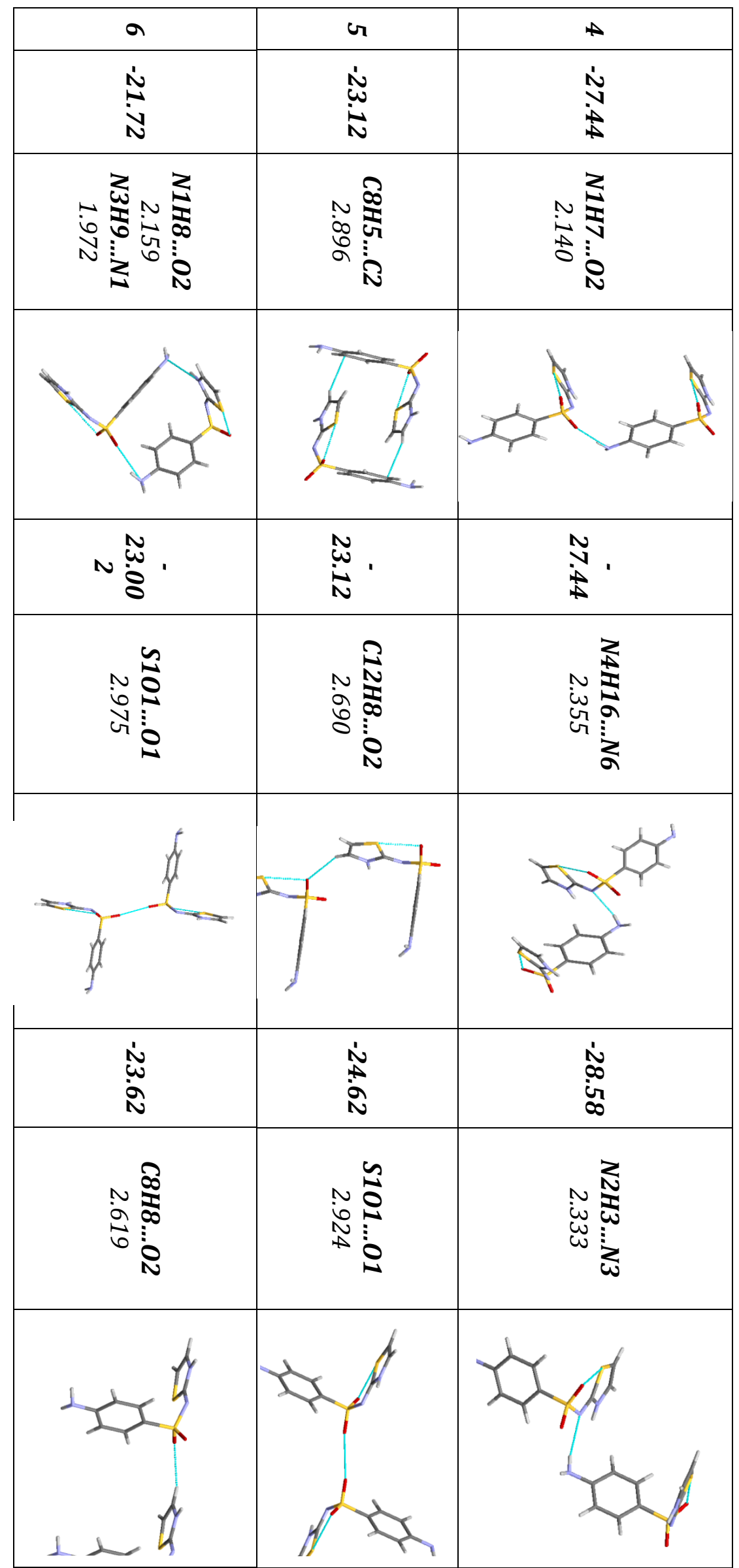




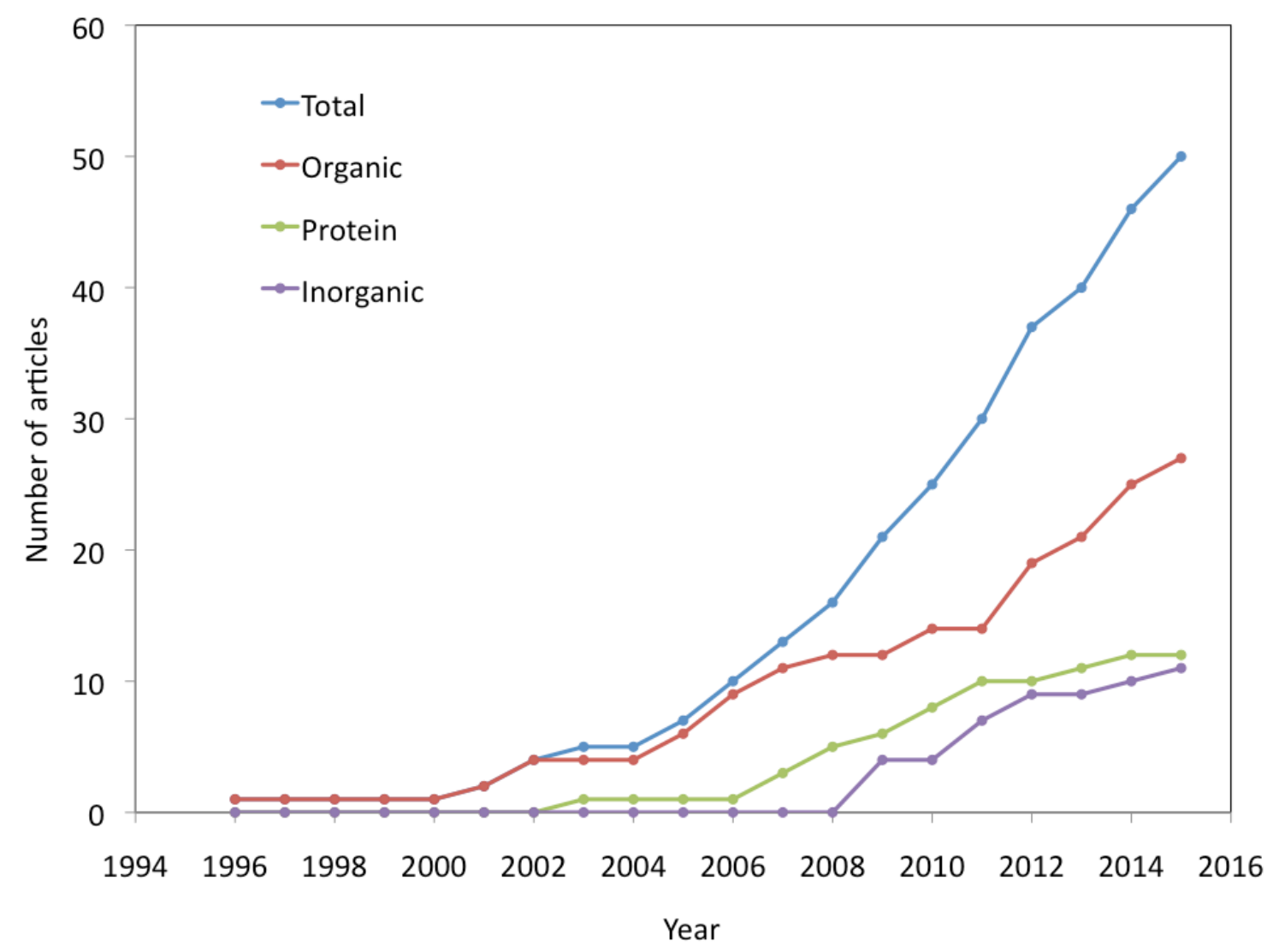

Figure S1 


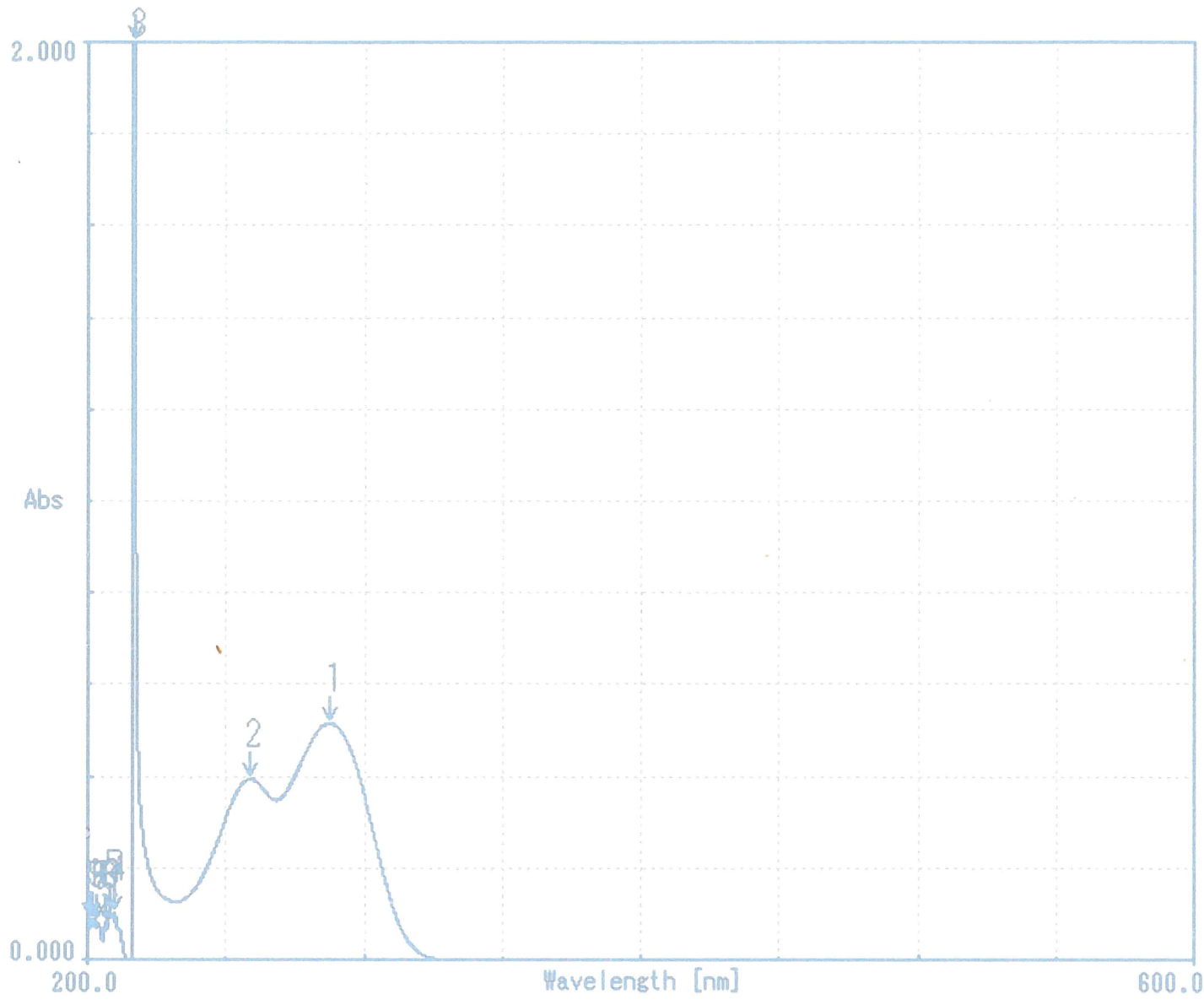

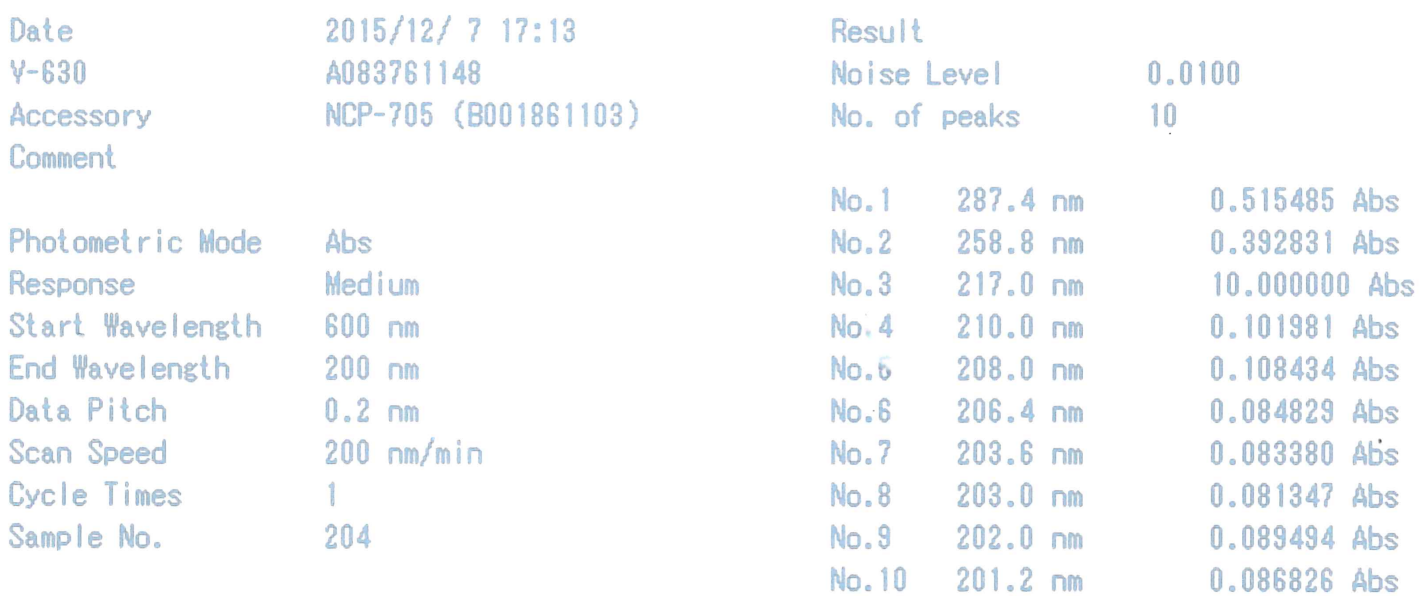

\section{Figure S2}




\section{LASER}

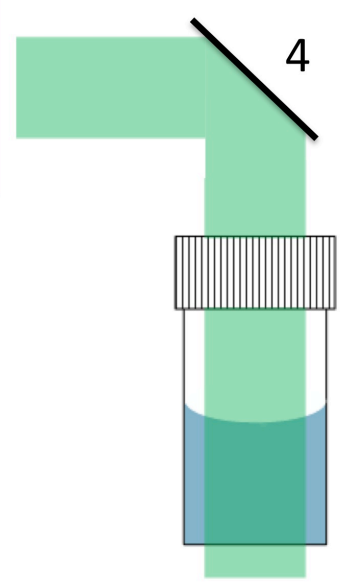

6
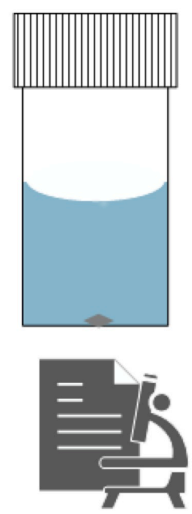

Figure S3 


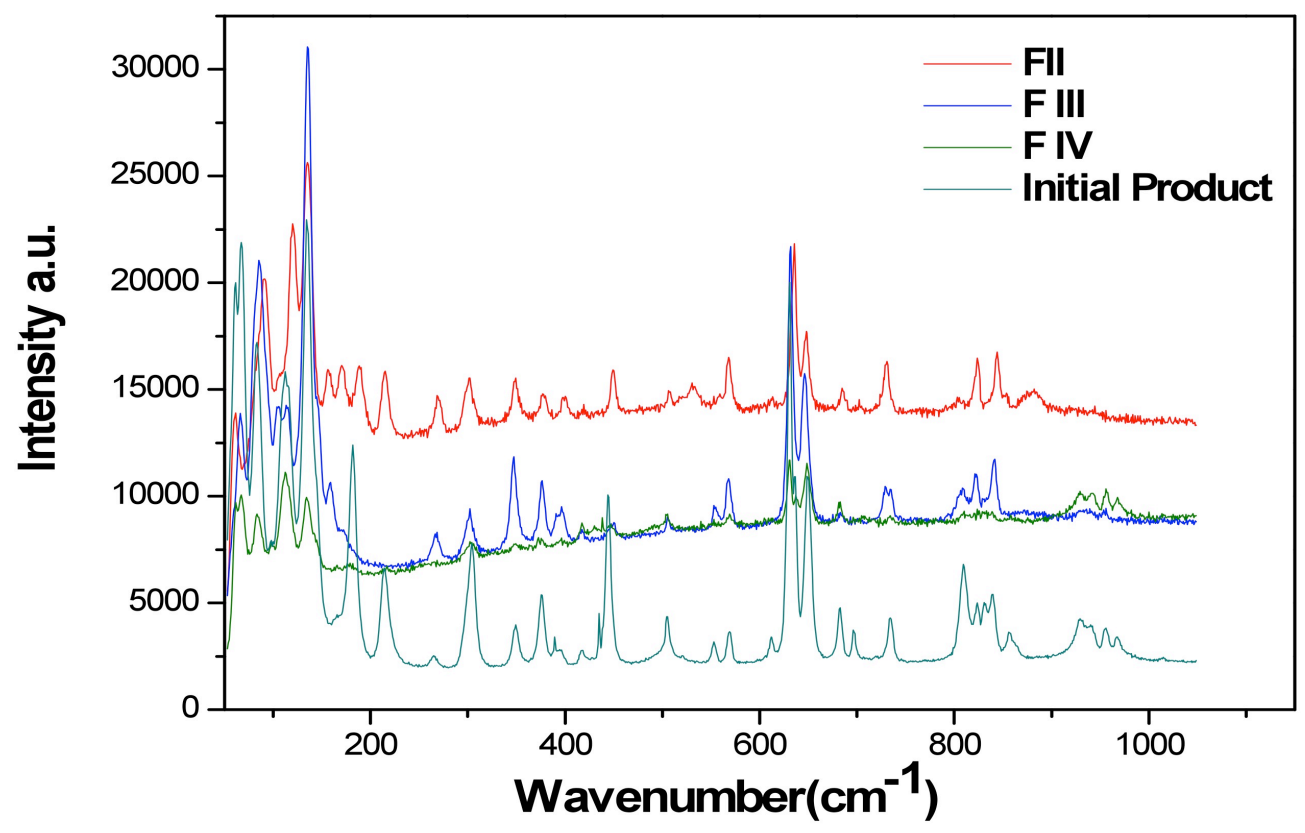

Figure S4 


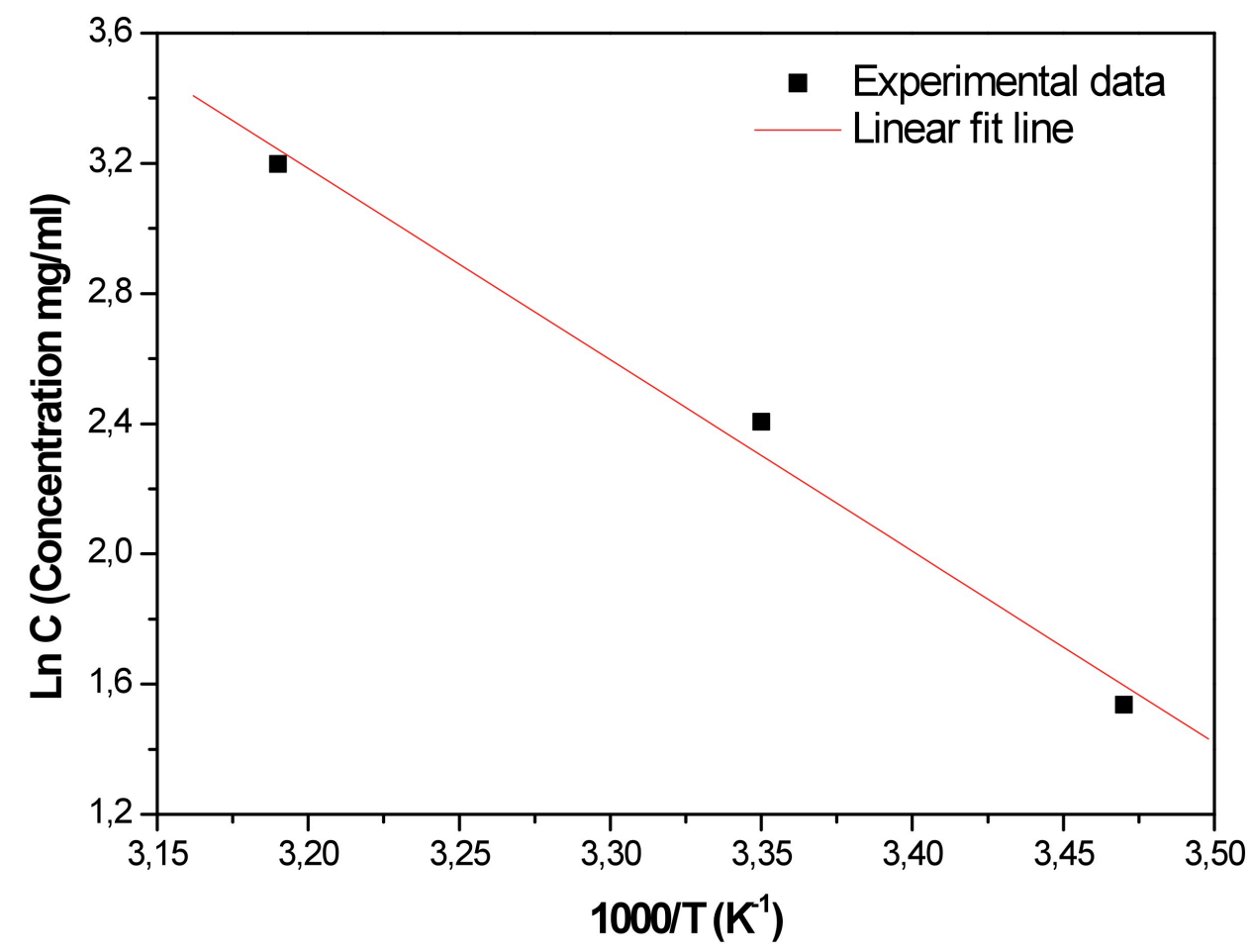

Figure S5 


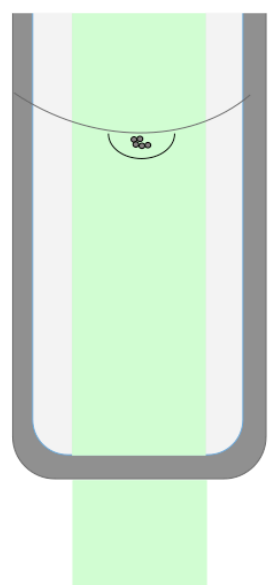

1

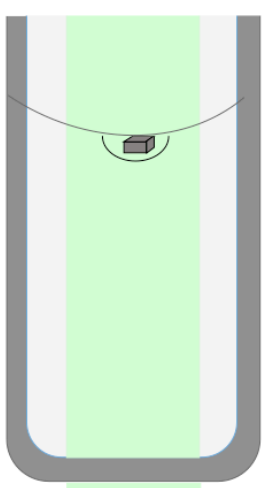

2

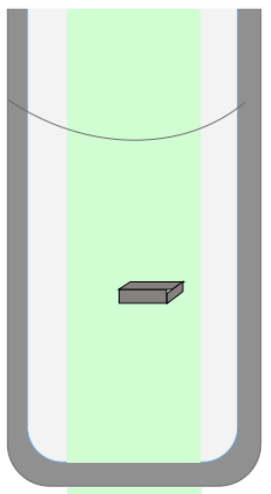

3

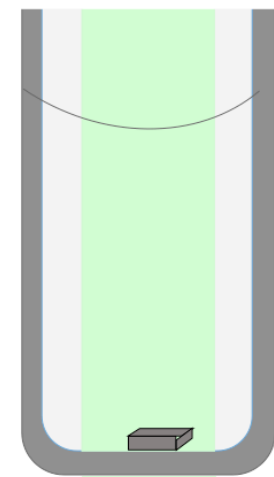

4

Figure S6 


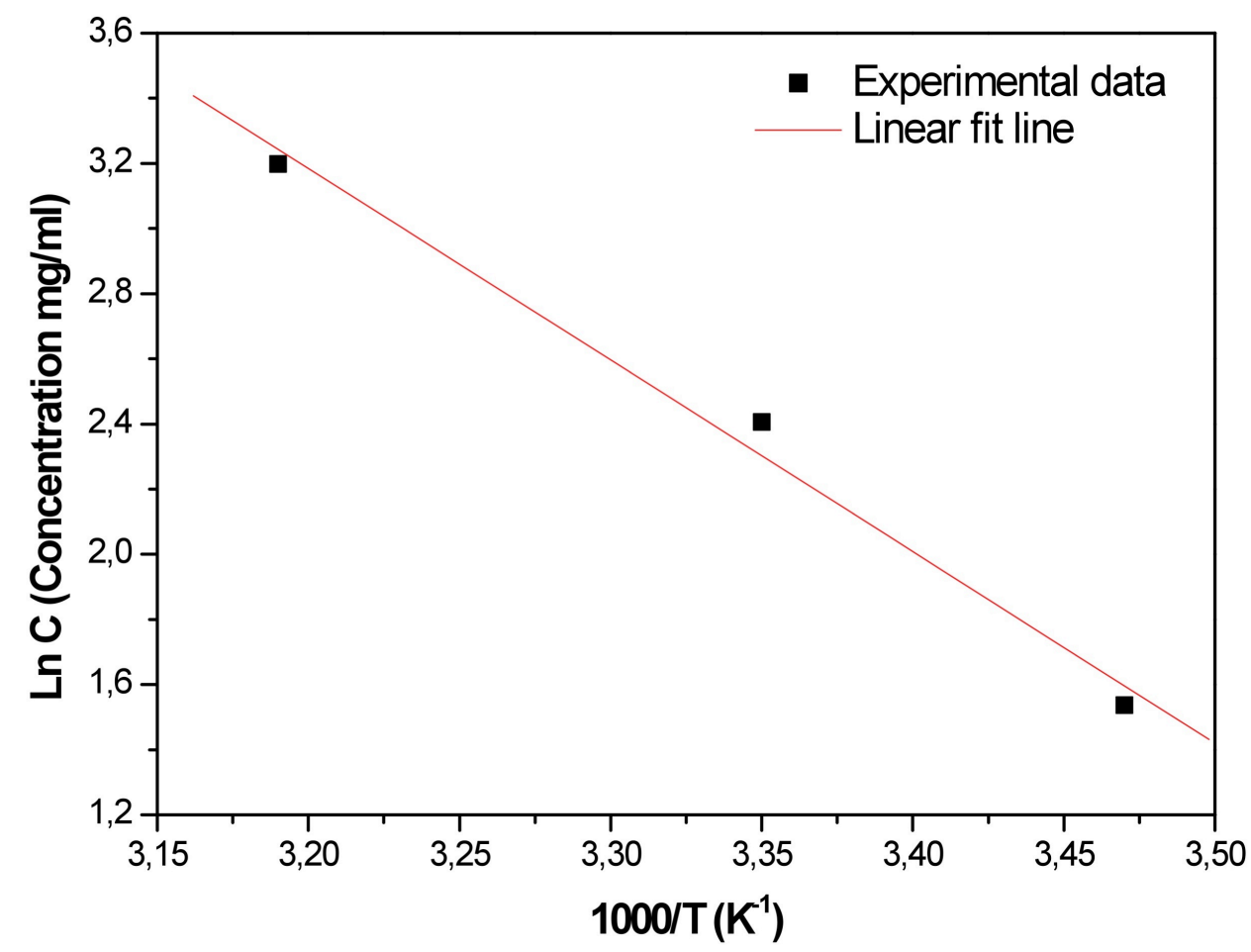

Figure S7 